\title{
ADVERSE EFFECTS AND SIDE EFFECTS ON VITAMIN THERAPY: A REVIEW
}

\author{
MEJO C KORAH*, JUNAID RAHMAN PV, RAJESWARI R, AHANA BEHANAN, ELIZABETH PHOEBA PAUL, \\ SIVAKUMAR T
}

Department of Pharmacology, Nandha College of Pharmacy and Research Institute, Erode, Tamil Nadu, India.

Email: mckpharma@gmail.com

Received: 10 January 2017, Revised and Accepted: 08 February 2017

ABSTRACT

Vitamins are essential for our daily life. Its shortage in our body can cause many disorders, decreased enzyme activities also affect the genetic factors. Vitamins should be supplied through the diet in the required amount. If it is not supplied properly, vitamin tablets will be prescribed. And also vitamin tablets are the co-medication for therapies such as anticancer, antitubercular, antiviral and anti-HIV treatments. Many newspapers reported that vitamin therapies are causing major health problems like nephro/urolithiasis, it can increase mortality rates in smokers by increasing the risk of lung cancer, it can cause abortion when it is taken during pregnancy. Thus here, we reviewed the adverse effects of vitamin therapy from various reported cases, books, instructions provided from various health organizations and also newspapers, and magazines. It can help health professionals to control and monitor the vitamin therapies and make awareness about the adverse effects and possible side effects of regular vitamin uptake to society.

Keywords: Vitamin, Adverse effects, Toxicity, Side effects.

(C) 2017 The Authors. Published by Innovare Academic Sciences Pvt Ltd. This is an open access article under the CC BY license (http://creativecommons. org/licenses/by/4. 0/) DOI: http://dx.doi.org/10.22159/ajpcr.2017.v10i5.17014

\section{INTRODUCTION}

Importance of vitamins was first recognized by the effects of their absence. The term "vitamin" was derived from the two words "vital" and "amine," as vitamins are considered essential for life and were originally thought to be amines. All vitamins are not amines except thiamine, they are organic compounds required by humans in small amounts from the diet to sustain life. An organic compound is considered a vitamin if a lack of that compound in the diet results in overt symptoms of deficiency [1]. After the isolation of vitamins in the laboratories, it came to the knowledge of medical science that there were deficiency diseases due to vitamins. Vitamins are organic substances needed by the body for normal metabolism, growth, and maintenance. They are not sources of energy but act as regulators of metabolic processes and as coenzymes in enzymatic systems [2].

According to vitaminology, vitamins are mainly classified as fat soluble vitamins and water soluble vitamins. Fat soluble vitamins are vitamin A, vitamin $\mathrm{D}$, vitamin $\mathrm{E}$, and vitamin $\mathrm{K}$. Water soluble vitamins are, namely, vitamin $\mathrm{C}$ and vitamin $\mathrm{B}\left(\mathrm{B}_{1}, \mathrm{~B}_{2}, \mathrm{~B}_{3}, \mathrm{~B}_{5}, \mathrm{~B}_{6}, \mathrm{~B}_{7}, \mathrm{~B}_{9}\right.$, and $\left.\mathrm{B}_{12}\right)$.

Deficiencies of vitamins can be either primary or secondary. A primary deficiency occurs when there is not enough of the vitamin in its food. A secondary deficiency may be due to an underlying disorder that limits the use of the particular vitamin which might be due to a "lifestyle factor," such as smoking, excessive alcohol consumption, or the use of medications that interfere with the absorption or use of the vitamin [3].

Although deficiency of vitamins causes disorders, overdose of vitamins has documented adverse reactions that tend to be more severe. At high doses, some vitamins cause side effects such as nausea, diarrhea, and vomiting $[4,5]$. When adverse reactions emerge in an individual, they got recovered when doses are decreased according to their individual tolerances which vary widely and appear to be related to age and health conditions.

The study published in the New England Journal of Medicine in 1994. 9,000 Finnish men, all were smokers, had been given vitamin E daily, beta-carotene, both or a placebo. The study was found that those who had taken beta-carotene for 5-8 years were more likely to die from lung cancer or heart disease.
About 2 years later the same journal published another study on vitamin supplements. In it, 18,000 people who were at an increased risk of lung cancer because of asbestos exposure or smoking received a combination of vitamin A and beta-carotene, or a placebo. Investigators stopped the study when they found that the risk of death from lung cancer for those who took the vitamins was $46 \%$ higher.

Then, in 2004, a review of 14 randomized trials for the Cochrane database found that the supplemental vitamins A, C, E and betacarotene, and a mineral, selenium, taken to prevent intestinal cancers, and actually increased mortality.

Another review, published in 2005 in the Annals of Internal Medicine, found that in 19 trials of nearly 13, 6000 people, supplement of vitamin E increased mortality. Also that year, a study of people with vascular disease or diabetes found that vitamin $\mathrm{E}$ increased the risk of heart failure. And in 2011, a study published in the Journal of the American Medical Association tied vitamin E supplements to an increased risk of prostate cancer.

In the year 2008, it was reported by 68,911 individuals to the American Association of Poison Control Centers (nearly $80 \%$ of these exposures were in children under the age of 6), that overdose exposure to all formulations of vitamins and multivitamin-mineral led to eight "major" life-threatening outcomes, but no deaths [6].

After reviewing several clinical trials, the University of Colorado stated that patients who took more vitamins had more health problems. Prof Tim Byers, the associate director for the cancer prevention at the university presented the findings that there is an increased risk of cancer on taking vitamins. Thus, the review can be made to understand and aware about the unwanted effects of all vitamin therapies and to take care of its uses to the health-care practitioners as well as peoples.

\section{VITAMIN A}

Vitamin A is an essential nutrient which is inevitable, but it cannot be synthesized in our body rather it should be obtained from our diet. It was the first vitamin to be officially named, so it became vitamin A [7]. It is fat soluble which get stored in the body and accumulates in high toxic levels when taken in large doses. It designates a group of retinoid 
compounds which involves retinol, retinal, retinoic acid and several provitamin A carotenoids, and beta-carotene with the biologic activity of all-trans retinol [8].

Different forms of vitamin A include beta-carotene, which is found in plants, and preformed vitamin A, which is found in animal sources. Beta-carotene is a double vitamin A molecule and must be converted to vitamin A in your body [7]

Vitamin A is found naturally in many foods. Vitamin A plays an essential role in a number of physiological functions that encompasses vision, embryonic development and reproduction, bone metabolism, hematopoiesis, skin and cellular health, immunity, gene transcription, and antioxidant activity $[9,10]$.

Vitamin A is one of the most widely studied nutrients in relation to immune function. It is a credible antioxidant for cancer prevention especially in treating skin cancer and lung cancer and helps in preventing other diseases as well. The recommended daily allowance for males is $900 \mu \mathrm{g} /$ day and for females is $700 \mu \mathrm{g} /$ day [11].

Vitamin A, though essential for our body, but it can cause various acute and chronic toxic effects. The overuse of vitamin A leads to abdominal pain, vomiting, headache, lethargy, eczema, patchy hair loss, edema, anemia, respiratory tract infection, and chronic liver disease. Toxic effects of vitamin A result from taking too much over time; betacarotene's only adverse effect is giving the skin an orange color [7]. Recently, it was found that beta-carotene can cause lung cancer and heart diseases to an extent of $20 \%$ according to the University of Colorado.

Vitamin A toxicity can be of two types: Acute toxicity and chronic toxicity:

Acute toxicity causes drowsiness, irritability, rash, abdominal pain, increased intracranial pressure, nausea, and vomiting.

Chronic toxicity causes changes in skin (dry and rough), hair (sparse and coarse) and nails, alopecia of the eyebrows, dry eyes, cracked lips; abnormal liver test results; in a fetus, birth defects (occur in children of women receiving isotretinoin which is related to vitamin A for acne treatment during pregnancy), increased intracranial pressure, and arthralgia; risk of fractures is increased, especially in the elderly. Hepatomegaly and splenomegaly may occur [12].

Intake from preformed sources of vitamin A often exceeds the recommended dietary allowances (RDA) for adults, especially in developed countries which show evidence of sub toxicity without clinical signs of toxicity of vitamin A. Osteoporosis and hip fracture are associated with preformed vitamin A intakes that are only twice the current RDA. As serum retinol concentrations are nonsensitive indicators to assess vitamin A status in persons with sub toxicity or toxicity levels, it is rather a complicated test in this range of liver vitamin A reserves $[13,14]$ performed a meta-analysis and concluded that the ingestion of large amounts of vitamin A as liver or oil-based supplements caused an increase in retinol, retinoic acid, and related retinoids.

Large intakes of vitamin A consumed by pregnant women will lead to fetal deformities which will include small ears or no ears, abnormal or missing ear canals, brain malformation, and heart defects.

Isotretinoin, a vitamin A metabolite used to treat acne, is hazardous to fetus with risk of malformations if a woman is exposed to isotretinoin during the first trimester and a woman who ceased taking isotretinoin 3 months before pregnancy still manifested teratogenic effects: Conjoined twins [15].

Alcohol consumption declines the hepatic levels of retinol (vitamin A) [16]. Alcoholics are generally malnourished and suffer from vitamin A deficiency which might lead to nyctalopia and xerophthalmia [17-19]. Active corneal xerophthalmia, severe malnutrition or measles demands high dose vitamin A treatment for infants and young children [20].

The WHO recommends two daily doses of vitamin A for children with measles living where deficiency is common; a practice associated with a reduced risk of mortality in children younger than 2 years old [21]

\section{VITAMIN B}

Vitamin B is essential for cell metabolism. It falls under the class of water soluble vitamins. There are eight types of vitamin B and they are chemically different. They are the following:

- Vitamin $\mathrm{B}_{1}$ (thiamine)

- Vitamin $B_{2}$ (riboflavin)

- Vitamin $B_{3}$ (niacin or nicotinic acid)

- Vitamin $B_{5}$ (pantothenic acid)

- Vitamin $\mathrm{B}_{6}$ (pyridoxine, pyridoxal, pyridoxamine)

- Vitamin $B_{7}$ (biotin)

- Vitamin $\mathrm{B}_{9}$ (folic acid)

- Vitamin $\mathrm{B}_{12}$ (various cobalamins)

Although many food items contain vitamin B, they are destroyed easily by alcohol and cooking. Also processing of food causes the decreasing of vitamin content. In meat and liver, B vitamins are higher in amount. Other sources of vitamin B are legumes (pulses) potatoes, bananas, chili, nutritional yeast, molasses, peppers, etc.

\section{Vitamin B}

It is involved in the metabolism of glucose and lipids as well as in the production of glucose derived neurotransmitters [22]. The recommended daily dose is $1.1 \mathrm{mg}$ for women and $1.2 \mathrm{mg}$ for men, lower levels are recommended for children and slightly higher levels, i.e., $1.4 \mathrm{mg}$ for pregnant and breast feeding women [23]. Due to inadequate thiamine intake, decreased absorption of thiamine from the gastrointestinal tract and impaired thiamine utilization in the cells, chronic alcohol consumption can result in thiamine deficiency [24]. Thiamine deficiency can lead to cell damage in central nervous system [25]. For various genetic disorders and thiamine deficiency syndromes such as beriberi and Wernicke-Korsakoff syndrome, thiamine is used for treatment. Although the optimal dose is unknown, oral thiamine is used in treating some conditions associated with diabetes, heart failure, and hypermetabolic states [26-29].

There are allergic reactions for thiamine but rare. At high intravenous doses ganglionic blockade occurs, though oral dosing of $3 \mathrm{~g}$ /day or even higher than that used for extended periods does not have deleterious effects [30-32]. Nausea and indigestion were reported in few subjects when they reached 7000 and $7500 \mathrm{mg} /$ day [31]. No side effects were reported in several clinical trials of thiamine derivatives for a variety of disorders that used doses between 300 and $900 \mathrm{mg}$ /day in divided doses for periods up to 3 months. No side effects were reported in these studies [33-35]. Gropper tells that overdose of thiamine by injection causes convulsions, cardiac arrhythmias, and anaphylactic shock [36].

\section{Vitamin $B_{2}$}

Riboflavin is also known as vitamin B-2 or vitamin B has an important role in the metabolism of carbohydrates, fats, and proteins in the body. Riboflavin is converted into flavin mononucleotide, which is then converted to the coenzyme, flavin adenine dinucleotide. Riboflavin deficiency can affect many enzyme systems and it can cause sore throat, redness and swelling of the lining of the mouth and throat, cracks or sores on the outside of the lips and at the corners of the mouth, anemia, seborrheic dermatitis, and formation of blood vessels in the cornea that interfere with vision. The dietary recommended dose of riboflavin ranges from $0.3 \mathrm{mg}$ daily for infants to $1.3 \mathrm{mg}$ daily for adult men. Pregnant women and nursing mothers require slightly more. Good sources of riboflavin include wheat flour and bread, dairy products, eggs, nuts, green vegetables, and meat. An earlier study reveals that riboflavin could reduce migraine attack frequency [37]. 
Riboflavin and light produces toxic peroxides [38,39], and riboflavintryptophan photoadduct causes liver damage and cell damage [40]. These affects seriously to patients and infants who are fed intravenously. In this riboflavin catalyzed reactions formed from room light irradiating the bags of liquid nutrition causes liver dysfunction [41,42]. Riboflavin found in skin and eyes cause many damaging effects of ultraviolet light exposure [43]. This include damage to connective tissue of skin [44], the induction of DNA lesions known to promote the development of skin cancer and aging $[45,46]$ and the impairment of mitochondria functioning resulting in cell death $[47,48]$.

\section{Vitamin $B_{3}$}

Niacin is also known as nicotinamide. Niacin improves circulation and also suppresses inflammation. It also helps to produce various sexes and stress-related hormones in the adrenal glands. Deficiency of niacin causes a condition called pellagra. Niacin has numerous beneficial lipid effects. Niacin has been used specifically for patients who have low high-density lipoprotein cholesterol and high triglyceride levels $[49,50]$ but long-term use leads to flushing, a common side effect. The flushing response is due to the prostaglandins [51,52]. Niacin reduces platelet counts [53] and affects clotting [54-57]

Adverse effects related to gastrointestinal, musculoskeletal, skin, and diabetes are also reported for niacin [58-62]. In a study of extended release niacin-laropiprant in high-risk patients shows that it did not significantly reduce the risk of major vascular events but significantly increased the risk of serious adverse events [62]. Gastrointestinal problems such as stomach bleeding, ulcers, diarrhea, and high sugar levels occurred in patient who had high dose niacin pill. Muscle pain, gout, infections, and brain bleeds were also common in niacin users.

\section{Vitamin $B_{5}$}

Also known as pantothenic acid plays a key role in the breakdown of fats and carbohydrates for energy, also essential for red blood cell and for the production of hormones. For maintaining a healthy digestive tract pantothenic acid is essential.

There were no severe adverse effects reported. Some gastrointestinal side effects such as nausea and heartburn have been reported [63]. Also a few cases of skin irritation, contact dermatitis, and eczema were reported with the use of dexpanthenol containing ointments $[64,65]$. Diarrhea was reported due to the intake of 10-20 g/day of calcium D-pantothenate [66]. There was a case report of life-threatening eosinophilic pleuropericardial effusion in a woman who took a combination of biotin and pantothenic acid for 2 months [67]. Pantothenic acid at high doses interact with biotin for intestinal and cellular uptake by the human sodium dependent multivitamin transporter $[68,69]$. Oral contraceptives which containing estrogen and progestin may increase the requirement for pantothenic acid [66]. Pantethine along with statins or with nicotinic acid may produce additive effects on blood lipids [63].

\section{Vitamin $B_{6}$}

Vitamin $B_{6}$ or pyridoxine improves the oxidative capacity of cells, thereby increases fatty acid oxidation in muscle and fat cell [70]. Deficiency of this vitamin may cause seizures in neonates [71]. Pyridoxine may cause nausea, vomiting, stomach pain, and sleepiness in some people. Excessive doses, i.e., more than $200 \mathrm{mg}$ of pyridoxine leads to sensory neuropathy and severe ataxia [72].

\section{Vitamin $B_{9}$}

Folic acid produces and maintains new cells. By blocking methylfolate, folic acid interferes with the natural history of anemia and nervous system manifestations [73]. Furthermore, folic acid enhances the electrical kindling model of epilepsy [74] and used to kindle seizures directly [75]. The excitatory properties of folates may block or reverse GABA-mediated inhibition [76,77]. Increased arousal; over activity, sleeplessness, and the rare precipitation of hypomania in predisposed persons are some studied side effects of folate therapy in pharmacological doses [78]. According to a review by the University of Colorado, a folic acid supplement which was thought to decrease precancerous polyps in the colon actually increased the number of polyps among users than who received placebo.

\section{Vitamin $B_{12}$}

Vitamin $B_{12}$ or cobalamin is essential for regulating nerve cells and also help in the production of genetic material. Even though anaphylactic reaction to vitamin $B_{12}$ is rare, it is a serious side effect especially administered via parental route [79]. The mechanism is proposed to be immunoglobulin E-mediated reaction [80]. A study also shows that metformin decreases vitamin $\mathrm{B}_{12}$ and folic acid levels [81].

\section{VITAMIN C}

Vitamin C or L-ascorbic acid, or ascorbate, is an essential nutrient for humans and certain other animal species. Ascorbic acid is structurally related to glucose and it is a weak sugar acid. In biological systems, ascorbic acid found only low $\mathrm{pH}$, but in neutral solutions above $\mathrm{pH} 5$ is predominantly found in the ionized form, ascorbate. In biological system ascorbate acts as a reducing agent, thus it has the ability of rapidly scavenging a number of reactive oxygen species (ROS) and can be reduced in the body by glutathione and nicotinamide adenine dinucleotide phosphate dependent enzymatic mechanisms $[82,83]$. Due to its antioxidant action, it is considered as antioxidants in the natural marine environment [84]. The daily requirements of vitamin C for an adult male recommends $90 \mathrm{mg}$ and no more than $2 \mathrm{~g} \mathrm{(2000} \mathrm{mg})$ per day and $75 \mathrm{mg}$ and not more than $2 \mathrm{~g}(2000 \mathrm{mg})$ per day for an adult female [85].

Vitamin C is used in various ailments like cancer, especially lung cancer [86,87] cardiovascular disease [88] and chronic diseases like rheumatoid arthritis [89], Alzheimer's disease (AD) [90,91] and also treatment of the common cold $[92,93]$, vitamin $C$ in combination with resveratrol found to be very effective in diabetes due it's synegestic effects [94]. And also clinical trials are undergoing with vitamin C are Roche European American Cataract Trial [95], the age-related eye disease study [96], and the simvastatin-niacin study shows that vitamin $\mathrm{C}$ at the doses of 750,500 , and $1000 \mathrm{mg}$ /day is safe [97].

There is some toxicity reported with vitamin C [98]. With the higher doses, toxic manifestations were observed in adults and infants. The signs and symptoms in adults were nausea, vomiting, diarrhea, flushing of the face, headache, fatigue, and disturbed sleep. The main toxic reactions in the infants were skin rashes, [99]. It is discussed that it may be due to the collagen synthetic reaction and enzymatic reactions with vitamin C. An epidemiologic investigation of vitamin C intake reported a relation with increased risk of cardiovascular disease (CVD) mortality in postmenopausal women with diabetes [100]. Vitamin C uptake, including from supplements, the mortality due to CVD in subjects who were nondiabetic at baseline.

As vitamin C can enhance iron absorption [101,102] iron poisoning can become an issue to patience with rare iron overload diseases like hemochromatosis. A genetic condition which results in decreased levels of the enzyme glucose-6-phosphate dehydrogenase may cause sufferers to develop hemolytic anemia after up taking specific oxidizing substances, like very large dosages of vitamin C. There are few reports of adverse effects other than mild osmotic diarrhea was also associated with vitamin C supplementation, and collectively the other hypothesized side effects are of undetermined relevance [103-106]. Intakes of vitamin C, if exceeded of $2000 \mathrm{mg} /$ day may sometimes been associated with the gastrointestinal upset or skin rashes, but other proofs suggest that intakes up to $4000 \mathrm{mg} /$ day are well tolerated in the general population.

Some case studies reported that unusually high intakes of vitamin C, especially persons who received vitamin intravenously or who is suffering with chronic renal failure, results in the development of oxalate kidney stones [107]. An epidemiologic study reported 
that the risk of nephrolithiasis is significantly lower in men who is consuming $\geq 1500 \mathrm{mg}$ vitamin C/D than in those who is consuming $<250 \mathrm{mg}$ vitamin C/D [108]. More evidence indicates that the "finding" of higher oxalate excretion in persons with high uptakes of vitamin $\mathrm{C}$ actually is an analytic artefact resulting from a method that can convert vitamin $\mathrm{C}$ in the test sample to oxalate in the analysis of the urine [109] and it is believed that there is a link between patients with oxalate deposits and a history of high dose vitamin C usage [110]. A few studies reported increased uric acid concentrations $[85,111,112]$ with the treatment of vitamin C.

In an experimental study conducted on rats, in the first month of pregnancy, high doses of vitamin C cause suppression of the production of progesterone from the corpus luteum [113]. By the blockage of this function of the corpus luteum, higher doses of vitamin C (1000 mg) are hypotheses to induce an early miscarriage. In a group of spontaneously aborting women at the end of the first trimester, the mean values of vitamin $\mathrm{C}$ were significantly higher in the entire aborting group.

\section{VITAMIN D}

Vitamin D is a fat-soluble vitamin comes under the category of secosteroids. The main functions of vitamin $\mathrm{D}$ in human are absorption of calcium, iron, magnesium, phosphate, and zinc. Around $90 \%$ of the vitamin $\mathrm{D}$ is obtained from sunlight, since vitamin D from sunlight is biologically inactive, its activation needs enzymatic conversion in the liver and kidney. There are two major types of vitamin $\mathrm{D}$ named vitamin $\mathrm{D}_{2}$ (ergocalciferol) and vitamin $\mathrm{D}_{3}$ (cholecalciferol).

Recent studies indicate that low serum concentrations of vitamin D are associated with prevalent $\mathrm{AD}$, dementia and cognitive impairment [114-116]. Vitamin D deficiency has also been related to vascular dysfunction and ischemic risk of stroke [117] as well as brain atrophy [118] and also potential anti-inflammatory activity [119].

Vitamin D toxicity, also called hypervitaminosis D, is a rare but potentially serious condition that occurs when the body has excessive amounts of vitamin D in the body [120]. An excess of vitamin D causes abnormally high blood concentrations of calcium, which can cause over calcification of the bones, soft tissues, heart, and kidneys. In addition, hypertension can result [121]. A case control study on a population in Southern India found that more than $50 \%$ of patients with ischemic heart disease had serum levels of vitamin D higher than $222.5 \mathrm{nmol} / \mathrm{L}$ (26). Excess of calciferol system appear to cause abnormal functioning, premature aging and natural homeostasis of vitamin D increase mortality [122-124]. Hypervitaminosis D associated with hypercalcemia with anorexia, nausea, weakness, weight loss, vague aches and stiffness, constipation, mental retardation, anemia, and mild acidosis.

It may also cause impairment of renal function with polyuria, nocturia, polydipsia, hypercalciuria, reversible azotemia, or irreversible renal insufficiency which may result in death. In this condition the occurrence of calcification of the soft tissues, including the heart, blood vessels, renal tubules, and lungs. Bone demineralization (osteoporosis) in adults occurs concomitantly.

It has been reported that vitamin $\mathrm{D}_{3}$ have the adverse effects such as cough, difficulty swallowing, dizziness, fast heartbeat, hives or itching, puffiness or swelling of the eyelids or around the eyes, face, lips, or tongue, skin rash, tightness in the chest, and unusual tiredness or weakness [125].

But high dosages of vitamin D may cause short term or long term side effects. Excess intake makes the intestines absorb too much calcium. Headache, nausea, vomiting, loss of appetite, dry mouth, abdominal or bone pain, muscle pain, fatigue, and dizziness are some of the symptoms of vitamin D toxicity. Itching, impaired kidney function, calcification of organs and blood vessels, osteoporosis, and seizures are other signs that develop at the later stages.
Side effects associated with taking vitamin D supplements typically occur following excessive or improper use of this nutrient. Excessively high levels of vitamin $\mathrm{D}$ in the body may elevate calcium levels, causing a condition called hypercalcemia. Unusually, high vitamin D levels in the body following treatment with vitamin D supplements may cause increased thirst. You may develop an unpleasant metallic taste in your mouth after taking a dose of vitamin D. This side effect may exacerbate upset stomach symptoms and can contribute to a loss of appetite. Excessive fatigue may make it difficult for you to remain focused, alert or attentive during normal daily activities, such as work or school. Talk with a medical professional if these side effects interfere with your ability to function normally [126]

\section{VITAMIN E}

Vitamin E refers to a group of compounds that include both tocopherols and tocotrienols [127]. $\alpha$-tocopherol, the most biologically active form of vitamin $\mathrm{E}$, is the second-most common form of vitamin $\mathrm{E}$ in the diet. Regular consumption of more than $1000 \mathrm{mg}$ (1500 IU) of tocopherols per day [128]. $\alpha$-tocopherol is an important lipid soluble antioxidant, and it protects cell membranes from oxidation by reacting with lipid radicals. Tocopherols are the lesser known but more potent antioxidants in the vitamin E family. It can protect neurons from damage [129] and cholesterol reduction [130].

It can cause some adverse effects such as blurred vision, diarrhea, dizziness, headache, nausea or stomach cramps, and unusual tiredness or weakness if it has taken more than $400 \mathrm{IU} /$ day [131].

\section{Angioplasty, a heart procedure}

Avoid taking supplements containing vitamin E or other antioxidant vitamins (beta-carotene, vitamin C) immediately before and following angioplasty without the supervision of a health-care professional. These vitamins interfere with proper healing.

\section{Diabetes}

Vitamin E might increase the risk of heart failure in people with diabetes. People with diabetes should avoid high doses of vitamin E.

\section{Heart attack}

Vitamin E might increase the risk for death in people with a history of heart attack. People with a history of heart attack should avoid high doses of vitamin E.

\section{An eye condition called retinitis pigmentosa}

All-rac-alpha-tocopherol (synthetic vitamin E) 400 IU seems to speed vision loss in people with retinitis pigmentosa. However, much lower amounts (3 IU) do not seem to produce this effect. If you have this condition, it is best to avoid vitamin $\mathrm{E}$.

\section{Bleeding disorders}

Vitamin E might make bleeding disorders worse. Patients with bleeding disorders, avoid taking vitamin E supplements.

\section{Head and neck cancer}

Do not take vitamin E supplements in doses of $400 \mathrm{IU} /$ day or more. Vitamin E might increase the chance that cancer will return.

\section{Prostate cancer}

There is concern that taking vitamin E might increase the chance of developing prostate cancer. The effect of vitamin $\mathrm{E}$ in men who currently has prostate cancer is not clear. However, in theory, the patients taking vitamin $\mathrm{E}$ worsen the prostate cancer who already having it.

\section{Stroke}

Vitamin E might increase the risk for death in people with a history of stroke.

\section{Surgery}

Vitamin E might increase the risk of bleeding during and after surgery. Stop using vitamin E at least 2 weeks before a scheduled surgery [132]. 


\section{VITAMIN K}

Vitamin K refers to a group of structurally similar, fat-soluble vitamins the human body needs for complete synthesis of certain proteins that are required for blood coagulation, and also certain proteins that the body uses to control binding of calcium in bone and other tissues. Chemically, the vitamin $\mathrm{K}$ family comprises 2-methyl-1, 4-naphthoquinone (3-) derivatives. Vitamin $\mathrm{K}$ includes two natural vitamins: Vitamin $\mathrm{K}_{1}$ and vitamin $\mathrm{K}_{2}$. Vitamin $\mathrm{K}_{1}$, also known as phylloquinone, phytomenadione, or phytonadione and vitamin $\mathrm{K}_{2}$ homologues are called menaquinones.

There is no serious adverse effects have been reported with vitamin $\mathrm{K}$. It is reported that it can cause an allergic reaction, especially with the higher dose of phylloquinone (vitamin $\mathrm{K}_{1}$ ) or menaquinone (vitamin $\mathrm{K}_{2}$ ). Unlike the safe natural forms of vitamin $\mathrm{K}_{1}$ and vitamin $\mathrm{K}_{2}$ and their various isomers, a synthetic form of vitamin $\mathrm{K}$, vitamin $\mathrm{K}_{3}$ (menadione), is demonstrably toxic. The U.S. Food and Drug Administration (FDA) has banned this form from over the counter sale in the United States because large doses have been shown to cause allergic reactions, hemolytic anemia, and cytotoxicity in liver cells [133]. The anaphylactoid reaction is mostly due to the conversion of vitamin $\mathrm{K}$ to its 2, 3 epoxide which may result in the anaphylactic reaction [134].

However, it is found that it can interact with anticoagulants like warfarin $[135,136]$ and coumarin. Warfarin works by blocking recycling of vitamin $\mathrm{K}$ so that the body and tissues have lower levels of active vitamin $K$, and thus a deficiency of vitamin K [137] and two separate studies in the rat model, after long-term administration of Coumadin to induce calcification of arteries in the rodents, supplemental vitamin $\mathrm{K}$ was found to reverse or prevent some of the arterial calcification attendant on the long-term blockade of vitamin K [138].

Vitamin $\mathrm{K}$ also interacts with cephalosporins (cefamandole, cefoperazone, cefmetazole, and cefotetan) tends to interact with vitamin $\mathrm{K}$ levels. Long-term use of antibiotics (more than 10 days) may result in vitamin $\mathrm{K}$ deficiency because these drugs can kill both harmful bacteria and vitamin K activating bacteria [139].

\section{CONCLUSION}

A vitamin is an organic compound and a vital nutrient that an organism requires in limited amounts. It can be converted into their active form in the body for the biological activity. It should be supplied through diet for the normal functioning of the body. In its malnutrition, vitamins should be supplied through the vitamin tablets. It is commonly used as the co-regimen for the chemotherapies, during pregnancy, etc. But magazines and newspapers like "The New york Times" reported that the usages of vitamins are increasing even without prescription. Thus, the adverse effects are due to its regular intake is increasing.

It is reported that vitamin $\mathrm{A}$ and $\mathrm{E}$ supplements not only provide no health benefits for generally healthy individuals, but they may increase mortality, though the two large studies that support this conclusion included smokers for whom it was already known that beta-carotene supplements can be harmful $[140,141]$. While other findings suggest that vitamin E toxicity is limited to only a specific form when taken in excess [129]. And also multivitamin tablets are dangerous to health those who are taking it regularly. Thus, health organizations such as FDA, the US Code of Federal Regulations, and the Food Supplements Directive are giving instructions for the vitamin therapies. Vitamin C, E and $\mathrm{A}$ and beta-carotene, vitamin $\mathrm{B}_{6}$, and multivitamin tablets are the top reported vitamins, which should not be taken as a regular dose.

So finally through the review, we are concluding that the vitamin intake should be monitored and controlled by the health practitioners regularly. Hence, the adverse effects, side effects, and toxicities can be controlled.

\section{REFERENCES}

1. Available from: http://www.lpi.oregonstate.edu/mic/vitamins.

2. Lutz C, Przytulski K. Vitamins. Nutrition and diet therapy. Nutri Notes:
Nutrition and Diet Therapy Pocket Guide. 5th ed. Philadelphia: F. A. Davis; 2011. p. 90-112

3. Larry E. Johnson, Over View of Vitamin, The Merck Mauel. Available from: http://www.merckmanuals.com.

4. Vitamin A: Fact Sheet for Health Professionals. National Institute of Health: Office of Dietary Supplements. 5 June; 2013. Available from: https://ods.od.nih.gov/factsheets/VitaminB6-HealthProfessional/. [Last retrieved on 2013 Aug 03]

5. Trumbo P, Yates AA, Schlicker S, Poos M. Dietary reference intakes: Vitamin A, vitamin K, arsenic, boron, chromium, copper, iodine, iron, manganese, molybdenum, nickel, silicon, vanadium, and zinc, J Am Diet Assoc 2001:101(3):294-301.

6. Bronstein AC, Spyker DA, Cantilena LR Jr, Green JL, Rumack BH, Giffin SL. 2008 Annual Report of the American Association of poison control centers National Poison Data System (NPDS): $26^{\text {th }}$ Annual Report. Clin Toxicol (Phila) 2009;47(10):911-1084.

7. Available from: http:/www./m.dummies.com/how-to/content/ how-your-body-uses-vitamina.html\&ei=03t $\quad 5 \mathrm{PNkE} \& \mathrm{Ic}=\mathrm{en}-\mathrm{IN} \&$ $\mathrm{s}=1 \& \mathrm{~m}=306 \& \mathrm{ts}=1438102313 \& \mathrm{sig}=$ AKQ9UOXSAz9Msqo VsY99AQFrUQs7vvKjA

8. Fennema O. Fennema's Food Chemistry. Boca Raton, FL: CRC Press, Taylor \& Francis; 2008. p. 454-5.

9. Sommer A, West KP Jr. Vitamin A Deficiency: Health, Survival and Vision. New York: Oxford University Press; 1996.

10. Villamor E, Fawzi WW. Effects of Vitamin A Supplementation on Immune Responses and Correlation with Clinical Outcomes. Boston, Massachusetts: Departments of Nutrition1 and Epidemiology, 2 Harvard School of Public Health; 2005.

11. Available from http://www.nap.edu.

12. Available from: http://www.msdmanuals.com/professional/nutritionaldisorders/vitamin-deficiency-dependency-and-toxicity/vitamin-A.

13. Penniston KL, Tanumihardjo SA. The acute and chronic toxic effects of vitamin A. Am J Clin Nutr 2006;83(2):191-201.

14. Myhre AM, Carlsen MH, Bøhn SK, Wold HL, Laake P, Blomhoff R. Water-miscible, emulsified, and solid forms of retinol supplements are more toxic than oil-based preparations. Am J Clin Nutr 2003;78(6):1152-9.

15. Malvasi A, Tinelli A, Buia A, De Luca GF. Possible long-term teratogenic effect of isotretinoin in pregnancy. Eur Rev Med Pharmacol Sci 2009;13(5):393-6.

16. Clugston RD, Blaner WS. Review on the Adverse Effects of Alcohol on Vitamin A Metabolism. New York: Department of Medicine and Institute of Human Nutrition College of Physicians and Surgeons, Columbia University; 2012

17. Lieber CS. Relationships between nutrition, alcohol use, and liver disease. Alcohol Res Health 2003;27(3):220-31.

18. Halsted CH. Nutrition and alcoholic liver disease. Semin Liver Dis 2004;24(3):289-304

19. Roncone DP. Xerophthalmia secondary to alcohol-induced malnutrition. Optometry 2006;77(3):124-33

20. Ross DA. Recommendations for vitamin A supplementation. J Nutr 2002;132 9 Suppl:2902S-6.

21. Huiming Y, Chaomin W, Meng M. Vitamin A for treating measles in children. Cochrane Database Syst Rev 2005;(4):CD001479.

22. Agabio R. Thiamine administration in alcohol dependent patient. Oxford J 2004;40(2):155-6.

23. Ambrose ML, Bowden SC, Whelan G. Thiamine treatment and working memory function of alcohol dependent people: Preliminary findings. Alcoholism. Clin Exp Res 2001;25(1):112-6.

24. Martin PR, Singleton CK, Hiller-Sturmhöfel S. The role of thiamine deficiencyin alcoholic brain disease. Alcohol Res Health 2003;27:134-42

25. Singleton CK, Martin PR. Molecular mechanisms of thiamine utilization. Curr Mol Med 2001;1(2):197-207.

26. Balakumar P, Rohilla A, Krishan P, Solairaj P, Thangathirupathi A. The multifaceted therapeutic potential of benfotiamine. Pharmacol Res 2010;61(6):482-8

27. Donnino MW, Carney E, Cocchi MN, Barbash I, Chase M, Joyce N, et al. Thiamine deficiency in critically ill patients with sepsis. J Crit Care 2010;25(4):576-81

28. Donnino MW, Cocchi MN, Smithline H, Carney E, Chou PP, Salciccioli J. Coronary artery bypass graft surgery depletes plasma thiamine levels. Nutrition 2010;26(1):133-6.

29. Soukoulis V, Dihu JB, Sole M, Anker SD, Cleland J, Fonarow GC, et al. Micronutrient deficiencies an unmet need in heart failure. J Am Coll Cardiol 2009;54(18):1660-73

30. Hartung E, Freye E. The effect of thiamine on the contractile responses 
of the isolated heart muscle. Acta Vitaminol Enzymol 1980;2(1-2):3-5.

31. Meador K, Loring D, Nichols M, Zamrini E, Rivner M, Posas H, et al. Preliminary findings of high-dose thiamine in dementia of Alzheimer's type. J Geriatr Psychiatry Neurol 1993;6(4):222-9.

32. Wolfson SK, Ellis S. Thiamine: Toxicity and ganglionic blockade. Fed Proc 1954;13:418.

33. Alkhalaf A, Klooster A, van Oeveren W, Achenbach U, Kleefstra N, Slingerland RJ, et al. A double-blind, randomized, placebo-controlled clinical trial on benfotiamine treatment in patients with diabetic nephropathy. Diabetes Care 2010;33(7):1598-601.

34. Stracke H, Gaus W, Achenbach U, Federlin K, Bretzel RG. Benfotiamine in diabetic polyneuropathy (BENDIP): Results of a randomised, double blind, placebo-controlled clinical study. Exp Clin Endocrinol Diabetes 2008;116:600-5.

35. Thornalley PJ. The potential role of thiamine (vitamin B1) in diabetic complications. Curr Diabetes Rev 2005;1:287-98.

36. Gropper SS, Smith JL, Groff JL. Advanced Nutrition and Human Metabolism. $5^{\text {th }}$ ed. Belmont, CA: Wadsworth; 2009.

37. Boehnke C, Reuter U, Flach U, Schuh-Hofer S, Einhäupl KM, Arnold G. High-dose riboflavin treatment is efficacious in migraine prophylaxis: An open study in a tertiary care centre. Eur J Neurol 2004;11(7):475-7.

38. Jernigan HM Jr. Role of hydrogen peroxide in riboflavin-sensitized photodynamic damage to cultured rat lenses. Exp Eye Res 1985;41(1):121-9.

39. Kale H, Harikumar P, Kulkarni SB, Nair PM, Netrawali MS. Assessment of the genotoxic potential of riboflavin and lumiflavin. B. Effect of light. Mutat Res 1992;298(1):17-23.

40. Silva E, Salim-Hanna M, Edwards AM, Becker MI, De Ioannes AE. A light-induced tryptophan-riboflavin binding: Biological implications. Adv Exp Med Biol 1991;289:33-48.

41. Chessex P, Lavoie JC, Rouleau T, Brochu P, St. Louis P, Levy E, et al. Photooxidation of parenteral multivitamins induces hepatic steatosis in a neonatal guinea pig model of intravenous nutrition. Pediatr Res 2002;52(6):958-63

42. Bhatia J, Moslen MT, Haque AK, McCleery R, Rassin DK. Total parenteral nutrition-associated alterations in hepatobiliary function and histology in rats: Is light exposure a clue? Pediatr Res 1993;33:487-92.

43. Edwards AM, Silva E. Effect of visible light on selected enzymes, vitamins and amino acids. J Photochem Photobiol B 2001;63(1-3):126-31.

44. Frati E, Khatib AM, Front P, Panasyuk A, Aprile F, Mitrovic DR. Degradation of hyaluronic acid by photosensitized riboflavin in vitro. Modulation of the effect by transition metals, radical quenchers, and metal chelators. Free Radic Biol Med 1997;22(7):1139-44.

45. Riemschneider S, Podhaisky HP, Klapperstück T, Wohlrab W. Relevance of reactive oxygen species in the induction of 8-oxo2'-deoxyguanosine in HaCaT keratinocytes. Acta Derm Venereol 2002;82:325-8

46. Oikawa S, Tada-Oikawa S, Kawanishi S. Site-specific DNA damage at the GGG sequence by UVA involves acceleration of telomere shortening. Biochemistry 2001;40:4763-8.

47. Salet C, Moreno G. Photodynamic action increases leakage of the mitochondrial electron transport chain. Int $\mathrm{J}$ Radiat Biol 1995;67(4):477-80.

48. Cho KS, Lee EH, Choi JS, Joo CK. Reactive oxygen species-induced apoptosis and necrosis in bovine corneal endothelial cells. Invest Ophthalmol Vis Sci 1999;40:911-9.

49. Stone NJ, Robinson J, Lichtenstein AH, Merz CN, Blum CB, Eckel RH, et al. 2013 ACC/AHA guideline on the treatment of blood cholesterol to reduce atherosclerotic cardiovascular risk in adults: A report of the American College of Cardiology, American Heart Association Task Force on Practice Guidelines. Circulation 2013;129:S1-45.

50. Task Force for the management of dyslipidaemias of the European Society of Cardiology (ESC) and the European Atherosclerosis Society (EAS), Catapano AL, Reiner Z, De Backer G, Graham I, Taskinen MR, et al. ESC/EAS Guidelines for the management of dyslipidaemias: The task force for the management of dyslipidaemias of the European Society of Cardiology (ESC) and the European Atherosclerosis Society (EAS). Atherosclerosis 2011;217 Suppl 1:S1-44.

51. Andersson RG, Aberg G, Brattsand R, Ericsson E, Lundholm L. Studies on the mechanism of flush induced by nicotinic acid. Acta Pharmacol Toxicol (Copenh) 1977;41:1-10.

52. Morgan JM, Capuzzi DM, Guyton JR. A new extended-release niacin (Niaspan): Efficacy, tolerability, and safety in hypercholesterolemic patients. Am J Cardiol 1998;82(12A):29U-34.

53. Guyton JR, Bays HE. Safety considerations with niacin therapy. Am J
Cardiol 2007;99(6A):22C-31.

54. Nagakawa Y, Orimo H, Harasawa M. The anti-platelet effect of niceritrol in patients with arteriosclerosis and the relationship of the lipid-lowering effect to the anti-platelet effect. Thromb Res 1985;40:543-53

55. Philipose S, Konya V, Lazarevic M, Pasterk LM, Marsche G, Frank S, et al. Laropiprant attenuates EP3 and TP prostanoid receptor-mediated thrombus formation. PLoS One 2012;7(8):e40222.

56. Chesney CM, Elam MB, Herd JA, Davis KB, Garg R, Hunninghake D, et al. Effect of niacin, warfarin, and antioxidant therapy on coagulation parameters in patients with peripheral arterial disease in the Arterial Disease Multiple Intervention Trial (ADMIT). Am Heart J 2000;140(4):631-6

57. Serebruany V, Malinin A, Aradi D, Kuliczkowski W, Norgard NB, Boden WE. The in vitro effects of niacin on platelet biomarkers in human volunteers. Thromb Haemost 2010;104(2):311-7.

58. The AIM-HIGH Investigators. Niacin in patients with low HDL cholesterol levels receiving intensive statin therapy. N Engl J Med 2011;365:2255-67.

59. Clofibrate and niacin in coronary heart disease. JAMA 1975;231:360-81.

60. Morgan JM, Capuzzi DM, Guyton JR. New extended-release niacin (Niaspan): Efficacy, tolerability, and safety in hypercholesterolemic patients. Am J Cardiol 1998;82:29U-34, 39U.

61. HPS2-THRIVE Collaborative Group. HPS2-THRIVE randomized placebo-controlled trial in 25673 high-risk patients of ER niacin/ laropiprant: Trial design, pre-specified muscle and liver outcomes, and reasons for stopping study treatment. Eur Heart J 2013;34:1279-91.

62. HPS-THRIVE Collaborative Group, Landray MJ, Haynes R, Hopewell JC, Parish S, Aung T, et al. Effects of extended-release niacin with laropiprant in high-risk patients. $N$ Engl $J$ Med 2014;371(3):203-12.

63. Hendler SS, Rorvik DR, editors. PDR for Nutritional Supplements. $2^{\text {nd }}$ ed. Montvale: Thomson Recuters; 2008.

64. Herbst RA, Uter W, Pirker C, Geier J, Frosch PJ. Allergic and nonallergic periorbital dermatitis: Patch test results of the information network of the departments of dermatology during a 5-year period. Contact Dermatitis 2004;51:13-9.

65. Schmuth M, Wimmer MA, Hofer S, Sztankay A, Weinlich G, Linder DM, et al. Topical corticosteroid therapy for acute radiation dermatitis: A prospective, randomized, double-blind study. $\mathrm{Br} \mathrm{J}$ Dermatol 2002;146:983-91.

66. Flodin N. Pharmacology of Micronutrients. New York: Alan R. Liss, Inc.; 1988.

67. Debourdeau PM, Djezzar S, Estival JL, Zammit CM, Richard RC, Castot AC. Life-threatening eosinophilic pleuropericardial effusion related to vitamins B5 and H. Ann Pharmacother 2001;35:424-6.

68. Said HM, Ortiz A, McCloud E, Dyer D, Moyer MP, Rubin S. Biotin uptake by human colonic epithelial NCM460 cells: A carriermediated process shared with pantothenic acid. Am J Physiol 1998;275:C1365-71.

69. Chirapu SR, Rotter CJ, Miller EL, Varma MV, Dow RL, Finn MG. High specificity in response of the sodium-dependent multivitamin transporter to derivatives of pantothenic acid. Curr Top Med Chem 2013; $13: 837-42$

70. Moore LR, Nehl F, Dorn J, Chalmers JJ, Zborowski M. Open gradient magnetic red blood cell sorter evaluation on model cell mixtures. IEEE Trans Magn 2013;49(1):309-15.

71. Hunt AD Jr, Stokes J Jr, Mccrory WW, Stroud HH. Pyridoxine dependency: Report of a case of intractable convulsions in an infant controlled by pyridoxine. Pediatrics $1954 ; 13(2): 140-5$.

72. Roman GC. Nutritional disorders of the nervous system. In: Shills ME, Shike M, Ross AC, Caballero B, Cousins RJ, editors. Modern Nutrition in Health and Disease. $10^{\text {th }}$ ed. Philadelphia, PA: Lippincott Williams \& Wilkins; 2006

73. Scott JM, Dinn JJ, Wilson P, Weir DG. Pathogenesis of subacute combined degeneration: A result of methyl group deficiency. Lancet 1981;2(8242):334-7.

74. Miller AA, Goff D, Webster RA. Predisposition of laboratory animals to epileptogenic activity of folic acid. In: Botez MI, Reynolds EH, editors. Folic Acid in Neurology, Psychiatry, and Internal Medicine. New York: Raven Press; 1979. p. 331-4.

75. O'Donnell RA, Leach MJ, Miller AA. Folic acid induced kindling in rats: Changes in brain amino acids. In: Blair JA, editor. Chemistry and Biology of Pteridines. Berlin: Walter de Gruyter; 1983. p. 801-5.

76. Davies J, Watkins JC. Facilitatory and direct excitatory effects of folate and folinate on single neurones of cat cerebral cortex. Biochem Pharmacol $1973 \cdot 22 \cdot 1667-8$ 
77. Hill RG, Miller AA. Antagonism by folic acid of presynaptic inhibition in the rat cuneate nucleus. Br J Pharmacol 1974;50:425-7.

78. Hunter R, Barnes J, Oakeley HF, Matthews DM. Toxicity of folic acid given in pharmacological doses to healthy volunteers. Lancet 1970;1:61-3.

79. Bilwani F, Adil SN, Sheikh U, Humera A, Khurshid M. Anaphylactic Reaction after Intramuscular Injection of Cyanocobalamin (Vitamin B12): A Case Report. Karachi: Department of Pathology. The Aga Khan University Hospital; 2005.

80. de Blay F, Sager MF, Hirth C, Alt M, Chamouard P, Baumann R, et al. IGE-mediated reaction to hydroxocobalamin injection in patient with pernicious anaemia. Lancet 1992 20;339:1535-6.

81. Wulffele MG, Kooy A, Lehert P, Bets D, Ogterop JC, Borger van der Burg B, et al. Effects of short-term treatment with metformin on serum concentrations of homocysteine, folate and vitamin B12 in Type 2 diabetes mellitus: A ran-domised, placebo-controlled trial. J Intern Med 2004;254:455-63.

82. Meister A. Glutathione-ascorbic acid antioxidant system in animals. J Biol Chem 1994;269:9397-400.

83. Michels A, Frei B. Vitamin C. In: Caudill MA, Rogers M, editors. Biochemical, Physiological, and Molecular Aspects of Human Nutrition. $3^{\text {rd }}$ ed. Philadelphia, PA: Saunders; 2012. p. 627-54.

84. Hardie LJ, Fletcher TC, Secombes CJ. The effect of dietary vitamin C on the immune response of the Atlantic salmon (Salmo salar L.). Aquaculture 1991;95(3-4):201-14

85. Food and Nutrition Board, Institute of Medicine. Dietary reference intakes for vitamin C, vitamin E, selenium, and carotenoids. A Report of the Panel on Dietary Antioxidants and Related Compounds, Subcommittees on Upper Reference Levels of Nutrients and Interpretation and Uses of Dietary Reference Intakes, and the Standing Committee on the Scientific Evaluation of Dietary Reference Intakes. Washington, DC: National Academy Press; 2000.

86. Luo J, Shen L, Zheng D. Association between vitamin C intake and lung cancer: A dose-response meta-analysis. Sci Rep 2014;4:6161.

87. Ye Y, Li J, Yuan Z. Effect of antioxidant vitamin supplementation on cardiovascular outcomes: A meta-analysis of randomized controlled trials. PLoS One 2013;8(2):e56803.

88. Rosenbaum CC, O’Mathúna DP, Chavez M, Shields K. Antioxidants and antiinflammatory dietary supplements for osteoarthritis and rheumatoid arthritis. Altern Ther Health Med 2010;16(2):32-40.

89. Cortés-Jofré M, Rueda JR, Corsini-Muñoz G, Fonseca-Cortés C, Caraballoso M, Bonfill Cosp X. Drugs for preventing lung cancer in healthy people. Cochrane Database Syst Rev 2012;10:CD002141.

90. Crichton GE, Bryan J, Murphy KJ. Dietary antioxidants, cognitive function and dementia - A systematic review. Plant Foods Hum Nutr 2013;68(3):279-92.

91. Li FJ, Shen L, Ji HF. Dietary intakes of vitamin E, vitamin C, and B-carotene and risk of Alzheimer's disease: A meta-analysis. J Alzheimers Dis 2012;31(2):253-8.

92. Douglas RM, Hemilä $\mathrm{H}$, Chalker E, Treacy B. Vitamin C for preventing and treating the common cold. Cochrane Database Syst Rev 2007;(3):CD000980.

93. Heimer KA, Hart AM, Martin LG, Rubio-Wallace S. Examining the evidence for the use of vitamin $\mathrm{C}$ in the prophylaxis and treatment of the common cold. J Am Acad Nurse Pract 2009;21(5):295-300.

94. Lalitha V, Korah MC, Sengottuvel S, Sivakumar T. Antidiabetic and antioxidant activity of resveratrol and Vitamin-C combination on streptozotocin induced diabetic rats. Int J Pharm Pharm Sci 2015;7(9):455-8.

95. Chylack LT Jr, Brown NP, Bron A, Hurst M, Köpcke W, Thien U, et al. The Roche European American Cataract Trial (REACT): A randomized clinical trial to investigate the efficacy of an oral antioxidant micronutrient mixture to slow progression of age-related cataract. Ophthalmic Epidemiol 2002;9(1):49-80.

96. Age-Related Eye Disease Study Research Group. A randomized, placebo-controlled, clinical trial of high-dose supplementation with vitamins $\mathrm{C}$ and $\mathrm{E}$, beta carotene, and zinc for age-related macular degeneration and vision loss: AREDS Report No 8. Arch Ophthalmol 2001;119(10):1417-36.

97. Brown BG, Zhao XQ, Chait A, Fisher LD, Cheung MC, Morse, JS, et al. Simvastatin and niacin, antioxidant vitamins, or the combination for the prevention of coronary disease. N Engl J Med 2001;345(22):1583-92.

98. Sauberlich HE. Pharmacology of vitamin C. Annu Rev Nutr 1994; 14:371-91.

99. Toxicological Evaluation of Some Food Additiveslincluding Anticaking Agents, Antimicrobials, Antioxidants, Emulsifiers and Thickening Agents. World Health Organization. July 4; 1973. Available from: http://www.inchem.org/documents/jecfa/jecmono/v05je01.

100. Heart Protection Study Collaborative Group. MRC/BHF Heart Protection Study of cholesterol-lowering therapy and of antioxidant vitamin supplementation in a wide range of patients at increased risk of coronary heart disease death: Early safety and efficacy experience. Eur Heart J 1999;20:725-41.

101. Fleming DJ, Tucker KL, Jacques PF, Dallal GE, Wilson PW, Wood RJ. Dietary factors associated with the risk of high iron stores in the elderly Framingham Heart Study cohort. Am J Clin Nutr 2002;76(6):1375-84

102. Cook JD, Reddy MB. Effect of ascorbic acid intake on nonheme-iron absorption from a complete diet. Am J Clin Nutr 2001;73(1):93-8.

103. Sano M, Ernesto C, Thomas RG, Klauber MR, Schafer K, Grundman $\mathrm{M}$, et al. A controlled trial of selegiline, alpha-tocopherol, or both as treatment for Alzheimer's disease. The Alzheimer's Disease Cooperative Study. N Engl J Med 1997;336(17):1216-22.

104. Rivers JM. Safety of high-level vitamin C ingestion. Int J Vitam Nutr Res Suppl 1989;30:95-102.

105. Diplock AT. Safety of antioxidant vitamins and beta-carotene. Am J Clin Nutr 1995;62 6 Suppl:1510S-6.

106. Balcke P, Schmidt P, Zazgornik J, Kopsa H, Haubenstock A. Ascorbic acid aggravates secondary hyperoxalemia in patients on chronic hemodialysis. Ann Intern Med 1984;101:344-5.

107. Curhan GC, Willett WC, Rimm EB, Stampfer MJ. A prospective study of the intake of vitamins $\mathrm{C}$ and B6, and the risk of kidney stones in men. J Urol 1996;155(6):1847-51.

108. Hathcock JN. Vitamins and minerals: Efficacy and safety. Am J Clin Nutr 1997;66(2):427-37.

109. Hoffer A. Ascorbic acid and kidney stones. Can Med Assoc J $1985 ; 132: 320$

110. Mashour S, Turner JF Jr, Merrell R. Acute renal failure, oxalosis, and vitamin $\mathrm{C}$ supplementation: A case report and review of the literature. Chest 2000;118(2):561-3.

111. Stein HB, Hasan A, Fox IH. Ascorbic acid-induced uricosuria. A consequency of megavitamin therapy. Ann Intern Med 1976;84(4):385-8

112. Levine M, Conry-Cantilena C, Wang Y, Welch RW, Washko PW, Dhariwal KR, et al. Vitamin C pharmacokinetics in healthy volunteers: Evidence for a recommended dietary allowance. Proc Natl Acad Sci U S A 1996;93(8):3704-9.

113. Ovcharov R, Todorov S. The effect of vitamin C on the estrus cycle and embryogenesis of rats. Akush Ginekol (Sofiia) 1974;13(3):191-5.

114. Balion C, Griffith LE, Strifler L, Henderson M, Patterson C, Heckman G, et al. Vitamin D, cognition, and dementia: A systematic review and meta-analysis. Neurology 2012;79:1397-405.

115. Annweiler C, Llewellyn DJ, Beauchet O. Low serum vitamin D concentrations in Alzheimer's disease: A systematic review and meta-analysis. J Alzheimers Dis 2013;33(3):659-74.

116. Annweiler C, Montero-Odasso M, Llewellyn DJ, Richard-Devantoy S, Duque G, Beauchet O. Meta-analysis of memory and executive dysfunctions in relation to vitamin D. J Alzheimers Dis 2013;37:147-71.

117. Dursun E, Gezen-Ak D, Yilmazer S. A novel perspectivefor Alzheimer's disease: Vitamin D receptor suppression byamyloid-b and preventing the amyloid-b induced alterations by Vitamin D in cortical neurons. J Alzheimers Dis 2011;23:207-19.

118. Abbas RS, Abdulridha MK, Shafek MA. Clinical evaluation of potential anti-inflammatory effect of vitamin $\mathrm{d} 3$ adjuvant therapy for chronic asthma in Iraqi patients. Int J Pharm Pharm Sci 2017;9(1):139-44.

119. Available from: http://www.mayoclinic.org/healthy-lifestyle/nutritionand-healthy-eating/expert answers/vitamin-d-toxicity/faq-20058108.

120. Brøndum-Jacobsen P, Nordestgaard BG, Schnohr P, Benn M 25-hydroxyvitamin D and symptomatic ischemic stroke: An original study and meta-analysis. Ann Neurol 2013;73:38-47.

121. Dionne JM, Abitbol CL, Flynn JT. Hypertension in infancy: Diagnosis, management and outcome. Pediatr Nephrol 2012;27(1):17-32.

122. Hsu JJ, Tintut Y, Demer LL. Vitamin D and osteogenic differentiation in the artery wall. Clin J Am Soc Nephrol 2008;3(5):1542-7.

123. Tuohimaa P. Vitamin D and aging. J Steroid Biochem Mol Biol 2009;114(1-2):78-84.

124. Keisala T, Minasyan A, Lou YR, Zou J, Kalueff AV, Pyykkö I, et al. Premature aging in vitamin D receptor mutant mice. J Steroid Biochem Mol Biol 2009;115(3-5):91-7.

125. Available from: http://www.drugs.com/sfx/vitamin-d3-side-effects

126. Available from: http:/www.livestrong.com/article/281042-negativeside-effects-of-taking-vitamin-d-supplements.

127. Brigelius-Flohé R, Traber MG. Vitamin E: Function and metabolism. FASEB J 1999;13(10):1145-55. 
128. Vitamin E - Health Professional Fact Sheet. Dietary-Supplements.info. 2015.

129. Sen CK, Khanna S, Roy S. Tocotrienols: Vitamin E beyond tocopherols. Life Sci 2006;78(18):2088-98.

130. Das S, Lekli I, Das M, Szabo G, Varadi J, Juhasz B, et al. Cardioprotection with palm oil tocotrienols: Comparison of different isomers. Am J Physiol Heart Circulatory Physiol 2008;294(2):H970-8.

131. Available from: http://www.drugs.com/sfx/vitamin-e-side-effects.

132. Available from: http://www.webmd.com/vitamins-supplements/ ingredientmono-954-vitamin $\% 20$ e.aspx?Activeingredientid=954\&active ingredient name $=$ vitamin $\% 20 \mathrm{e}$.

133. Higdon J. Vitamin K. Linus Pauling Institute, Oregon State University. Available from: http:/www.lpi.oregonstate.edu/infocenter/vitamins/ vitaminK.

134. Fiore LD, Scola MA, Cantillon CE, Brophy MT. Anaphylactoid reactions to vitamin $\mathrm{K}$. J Thromb Thrombolysis 2001;11(2):175-83.

135. Ansell J, Hirsh J, Poller L, Bussey H, Jacobson A, Hylek E. The pharmacology and management of the vitamin $\mathrm{K}$ antagonists: The Seventh ACCP Conference on Antithrombotic and Thrombolytic Therapy. Chest 2004;126 3 Suppl:204S-33.

136. Crowther MA, Douketis JD, Schnurr T, Steidl L, Mera V, Ultori C, et al.
Oral vitamin $\mathrm{K}$ lowers the international normalized ratio more rapidly than subcutaneous vitamin $\mathrm{K}$ in the treatment of warfarin-associated coagulopathy. A randomized, controlled trial. Ann Intern Med 2002;137(4):251-4.

137. Important Information to Know When You Are Taking: Warfarin (Coumadin) and Vitamin K, National Institutes of Health; 2015. Available from: http://www.ods.od.nih.gov/pubs/factsheets/ coumadin1.pdf. [Last retrieved on 2015 Jun 17].

138. Schurgers LJ, Spronk HM, Soute BA, Schiffers PM, DeMey JG, Vermeer C. Regression of warfarin-induced medial elastocalcinosis by high intake of vitamin $\mathrm{K}$ in rats. Blood 2007;109(7):2823-31.

139. Available from: http://www.umm.edu/health/medical/altmed/supplementinteraction/possible-interactions-with-vitamin-k.

140. Moyer VA; U.S. Preventive Services Task Force. Vitamin, mineral, and multivitamin supplements for the primary prevention of cardiovascular disease and cancer: U.S. Preventive services Task Force recommendation statement. Ann Intern Med 2014;160(8):558-64.

141. Bjelakovic G, Nikolova D, Gluud LL, Simonetti RG, Gluud C. Mortality in randomized trials of antioxidant supplements for primary and secondary prevention: Systematic review and meta-analysis. JAMA 2007;297(8):842-57. 